\title{
BOOSTER RING CORRECTION MAGNETS
}

BOOSTER TECHNICAL NOTE

NO. 224

\author{
R. Thern
}

May 20, 1994

\section{ALTERNATING GRADIENT SYNCHROTRON DEPARTMENT}

BROOKHAVEN NATIONAL LABORATORY

UPTON, NEW YORK 11973 


\title{
BOOSTER RING CORRECTION MAGNETS
}

\author{
R. Thern
}

May 20, 1994

\section{INTRODUCTION}

The Booster correction magnets are mounted at the upstream end of the sextupoles in each half cell. Most of the correctors are of one standard design, except in four locations where special correctors are needed to avoid interference with external lines and the dump.

The standard correction package has several windings, which may be hooked up to give skew quadrupole, and a choice of either horizontal or vertical dipole. The special correctors are horizontal dipole only. For control purposes, these magnets are named with the prefixes DHC, DVC, and QSC.

Each corrector in the ring is powered with a bipolar $25 \mathrm{~A}$ supply. For the tests presented here, they have been powered as high as $50 \mathrm{~A}$ for a short period. They would get quite hot if powered continuously at this level, especially in the ring, where the air cannot circulate freely on all sides of the coils.

Three standard correction packages, serial numbers 25, 26, and 27, were measured by the Testing and Measuring Group of ADD in Building 902, using the same rotating coil that was used to measure the other booster magnets. This gives the harmonics of the field, integrated longitudinally through the magnet. The four special dipoles were measured with a Hall probe along the central axis, so there is no harmonic information available for them.

\section{STANDARD DIPOLE}

Figure 1 shows the excitation curves for the correction dipoles. Three magnets were tested, with each hooked up as a vertical and a horizontal dipole, giving six data sets. The magnets were tested in place on the sextupole, so these results properly reflect the effect of the nearby iron on the field. The data shown all have the field measured at $0 \mathrm{~A}$ - about $1 \mathrm{G}-\mathrm{m}$, due (mainly) to the earth's field - subtracted.

The field in the correctors is typically $0.975 \mathrm{G}-\mathrm{m} / \mathrm{A}$ (Gauss-meters/Ampere). The saturation is negligible up to the $25 \mathrm{~A}$ design current, increasing to $6 \%$ at $50 \mathrm{~A}$. For the sample of six magnets measured (three units with two orientations), the variation in transfer function is about $1 \% \mathrm{rms}$.

The integrated field for a very short dipole like this is less than would be calculated by using the simple rule of thumb of adding one-half gap of extra magnetic length at each end. For this magnet one would calculate, using the dimensions from Figure 7 and combining the components at $\pm 45^{\circ}$,

$$
\begin{aligned}
\frac{B}{I} & =\sqrt{2} \frac{\mu_{0} N}{g} \\
& =\sqrt{2} \frac{4 \pi \cdot 10^{-7} \cdot(47+5+5)}{9 \cdot 0.0254} \\
& =4.43 \cdot 10^{-4} T / A=4.43 \mathrm{G} / A,
\end{aligned}
$$




$$
\begin{aligned}
\frac{B \cdot d l}{I} & =4.43 \cdot(6+9) \cdot 0.0254 \\
& =1.69 \mathrm{G}-m / A .
\end{aligned}
$$

This is to be compared with the measured value of $0.975 \mathrm{G}-\mathrm{m} / \mathrm{A}$.

\section{HYSTERESIS}

For one magnet, measurements were made with both rising and falling current in an attempt to measure the hysteresis. The resulting curves for the dipole are shown in Figure 2. The maximum width of the hysteresis curve is about $0.15 \mathrm{G}-\mathrm{m}$, which is equivalent to a current change of $0.15 \mathrm{~A}$. This is a small effect and need be accounted for only if current changes of this magnitude are found to be significant.

\section{SKEW QUAD}

The excitation curve for the skew quad is shown in Figure 3. The transfer function is $.0545 \mathrm{G}-\mathrm{m} / \mathrm{cm}-\mathrm{A}$. There is no hint of saturation even at $50 \mathrm{~A}$. The variation in a sample of three is $0.7 \% \mathrm{rms}$.

\section{CROSSMODULATION}

Since the dipole and quadrupole share the same iron, they may affect each other. This was tested by powering both windings in a matrix up to $50 \mathrm{~A}$ each. Some results are shown in Figure 4. Below $25 \mathrm{~A}$ the crossmodulation is unmeasurable. With $50 \mathrm{~A}$ in the dipole, the skew quad transfer function is reduced by about $15 \%$. The shape of the curve differs for the two magnets, as shown in the figure; this is not understood.

The skew quadrupole also affects the dipole (not shown). The dipole excitation curve is essentially unchanged for skew quad currents up to $30 \mathrm{~A}$. Above that, there is more saturation in the dipole curves, reaching $15 \%$ (instead of $6 \%$ ) with $50 \mathrm{~A}$ in both windings. negligible.

At actual working currents, which will be below $25 \mathrm{~A}$, the crossmodulation appears

\section{SEXTUPOLE IN DIPOLE MAGNET}

There is a potentially significant sextupole component in the standard correction dipole, as shown in Figure 5. The end field of a dipole typically has a lot of sextupole, and for these short magnets the end field is a large contributor to the total integrated field. Note that the orientation of the sextupole component is the same as the driven dipole - normal sextupole for horizontal dipole (vertical field) and skew sextupole for vertical dipole.

The correction dipoles will be powered in some pattern around the ring to correct the orbit at injection. This will introduce a similar pattern of sextupole field, which can be compared with the tolerance for random sextupole in the main dipoles. With the corrector powered to $25 \mathrm{~A}$, and the main dipole at the proton injection field $(\mathrm{B} . \mathrm{dl}=3751 \mathrm{G}-\mathrm{m} / \mathrm{A})$, the sextupole from the corrector is equivalent to 


$$
\begin{aligned}
b_{2} & =b_{2 \text { (corrector) }} \cdot \frac{B \cdot d l_{(\text {corrector) }}}{B \cdot d l_{(\text {dipole) }}} \\
& =.00045 \cdot 0.975 \cdot 25 / 3751 \\
& =3 \cdot 10^{-6} \mathrm{~cm}^{-2} .
\end{aligned}
$$

This is comparable to the stated tolerance of $5 \times 10^{-6} \mathrm{~cm}^{-2}$ for random $b_{2}$ in the dipole '. In actuality, there should be no problem here. The correctors should be powered at well under $25 \mathrm{~A} \mathrm{rms}$, and since the correctors are for orbit correction, they should be powered with harmonics like $5 \theta$, and not at 14 or $15 \theta$ which would affect sextupole stopbands.

\section{SPECIAL DIPOLES}

At four locations in the ring ( $\mathrm{C} 4, \mathrm{C} 6, \mathrm{D} 6$, and $\mathrm{F} 6)$ the standard corrector package could not be used and special magnets were installed. These are dipoles only. Due to time constraints, they could not be measured with the rotating coil. Instead, the field at $25 \mathrm{~A}$ was measured with a Hall probe at intervals of one inch or less down the centerline. The data are shown in Figure 6.

These are not to be considered precision measurements. Except for $\mathrm{C} 4$, the field at $0 \mathrm{~A}$ was not measured or corrected for-the polarity of the measurement is unknown so we cannot merely subtract approximately $0.5 \mathrm{G}$ for the earth's field. The magnets when measured were standing free, but when used will be close to the sextupole, which will affect the fringe field on one side. The transfer functions in Table 1 were obtained by numerically integrating the data from Figure 6.

No measurements were made which might show the higher harmonics of the four special dipoles. Since they are shorter than the standard corrector, and mounted closer to the sextupole, they will probably have a larger harmonic content.

\section{SUMMARY}

The results are given in tabular form in Table 1. Figures 7 and 8 show the dimensions of the magnets.

These magnets were designed by John Brodowski, who supplied Figures 7 and 8 . The measurements were done by R. Riesen, A. Sauerwald, J. Brodowski, and the author.

\section{REFERENCES}

1. A Ruggiero, Memo to W. Weng, 1/23/90. 


\begin{tabular}{|c|c|c|c|c|}
\hline \multicolumn{5}{|c|}{ I. Dipole $(\mathrm{H}$ or $\mathrm{V})$} \\
\hline Standard & $0.975 \pm 1 \%$ & $\mathrm{G} \mathrm{m} / \mathrm{A}$ & $9.75 \times 10^{-5}$ & $\mathrm{~T} \mathrm{~m} / \mathrm{A}$ \\
\hline $\mathrm{C} 4$ & 1.06 & $\mathrm{G} \mathrm{m} / \mathrm{A}$ & $1.06 \times 10^{-4}$ & $\mathrm{~T} \mathrm{~m} / \mathrm{A}$ \\
\hline C6 & 1.00 & $\mathrm{Gm} / \mathrm{A}$ & $1.00 \times 10^{-4}$ & $\mathrm{~T} \mathrm{~m} / \mathrm{A}$ \\
\hline D6 & 1.43 & $\mathrm{G} \mathrm{m} / \mathrm{A}$ & $1.43 \times 10^{-4}$ & $\mathrm{~T} \mathrm{~m} / \mathrm{A}$ \\
\hline F6 & 1.32 & $\mathrm{G} \mathrm{m} / \mathrm{A}$ & $1.32 \times 10^{-4}$ & $\mathrm{~T} \mathrm{~m} / \mathrm{A}$ \\
\hline \multicolumn{5}{|c|}{ II. Skew Quad } \\
\hline Standard & $0.0545 \pm .7 \%$ & $\mathrm{G} \mathrm{m} /(\mathrm{cm} \mathrm{A})$ & $5.45 \times 10^{-4}$ & $\mathrm{~T} / \mathrm{A}$ \\
\hline \multicolumn{5}{|c|}{ III. Sextupole Component of Dipole (Normal or Skew) } \\
\hline Standard & 0.0004 & $\mathrm{G} \mathrm{m} /\left(\mathrm{cm}^{2} \mathrm{~A}\right)$ & $4.5 \times 10^{-4}$ & $\mathrm{~T} / \mathrm{m} \mathrm{A}$ \\
\hline
\end{tabular}

Table 1. Transfer functions for the Booster ring correction magnets. 


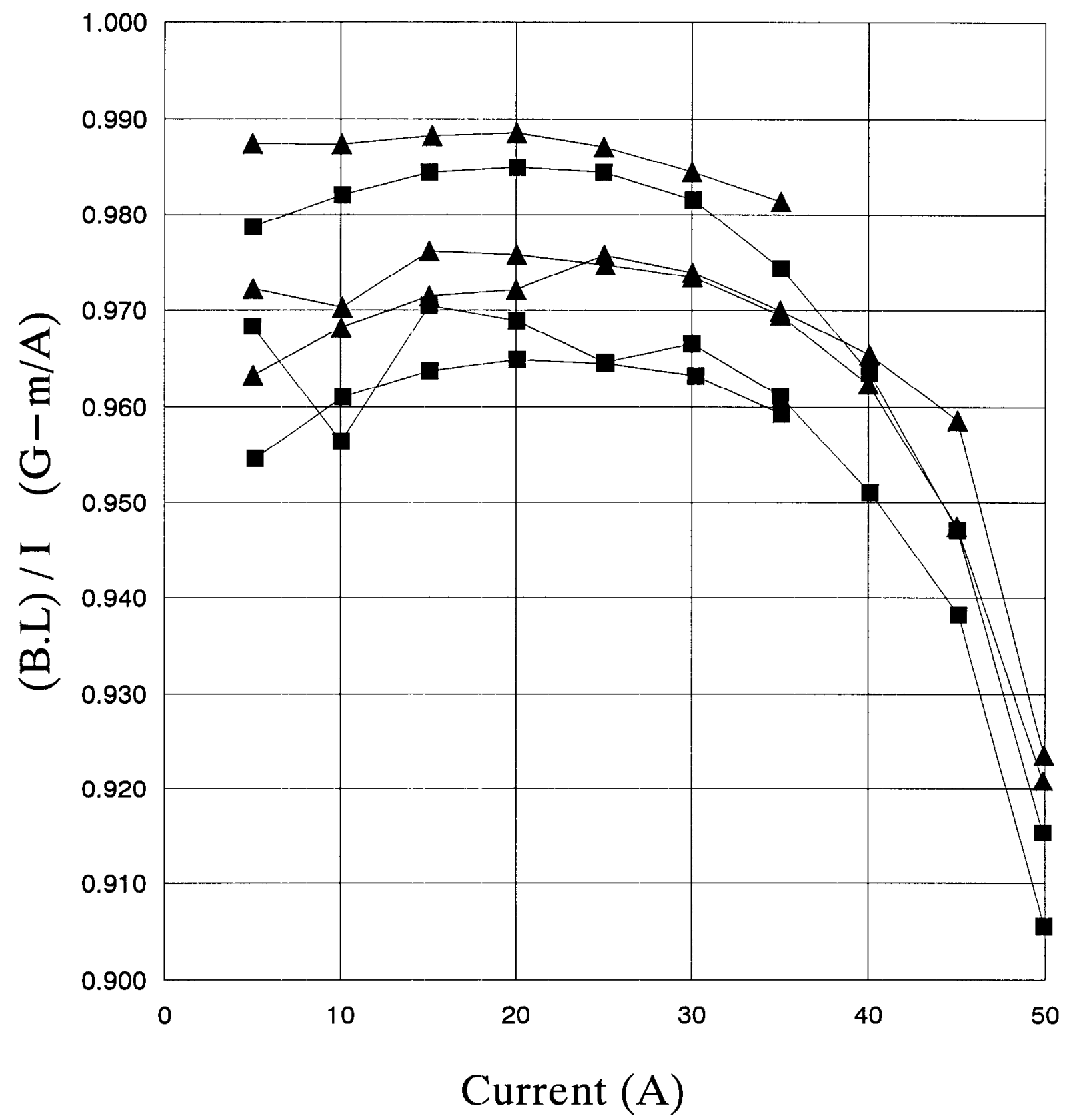

- Vertical ^ Horizontal

Figure 1. Typical dipole transfer function curves for the standard Booster Correction Package. The data extends to $50 \mathrm{~A}$ even though the operating range is only $25 \mathrm{~A}$. 


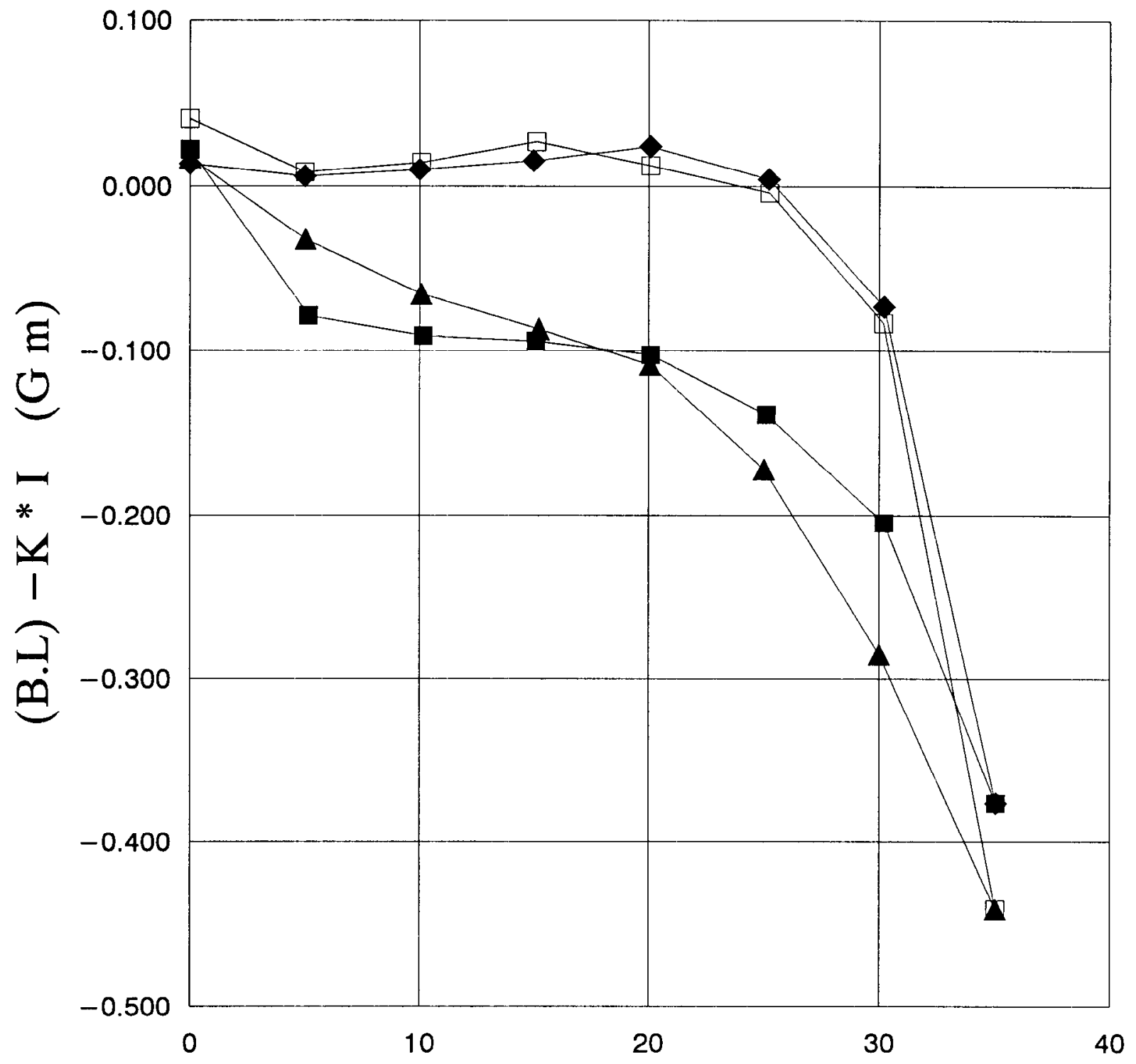

Current (A)

$$
-\mathrm{VD}-\mathrm{up} \leftarrow \mathrm{VD}-\mathrm{dn} \_\mathrm{HD}-\mathrm{up} \leftarrow \mathrm{HD}-\mathrm{dn}
$$

$K$ value: $V=.970, H=.994(G-m) / A$

Figure 2. Typical dipole hysteresis curve. Note that this is for a monopolar cycle to $35 \mathrm{~A}$, and a bipolar cycle to $25 \mathrm{~A}$ would be slightly narrower at the high end and would not come together at zero. 


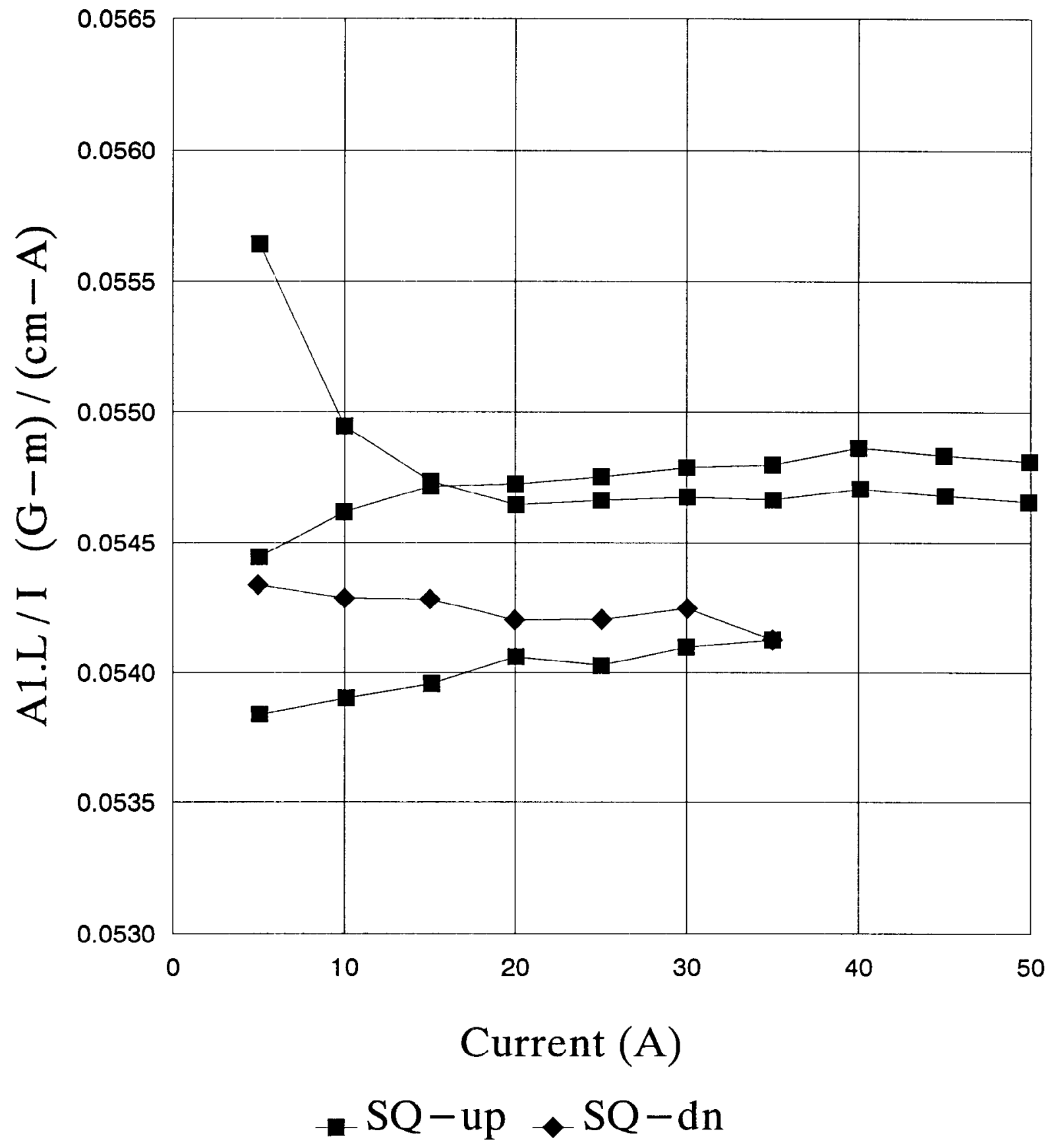

Figure 3. Typical skew quad transfer function curves for the Booster Correction Package. Again, the data extends to $50 \mathrm{~A}$ even though the operating range is only 25 A. One magnet was measured both rising and falling to show the effect of hysteresis. 


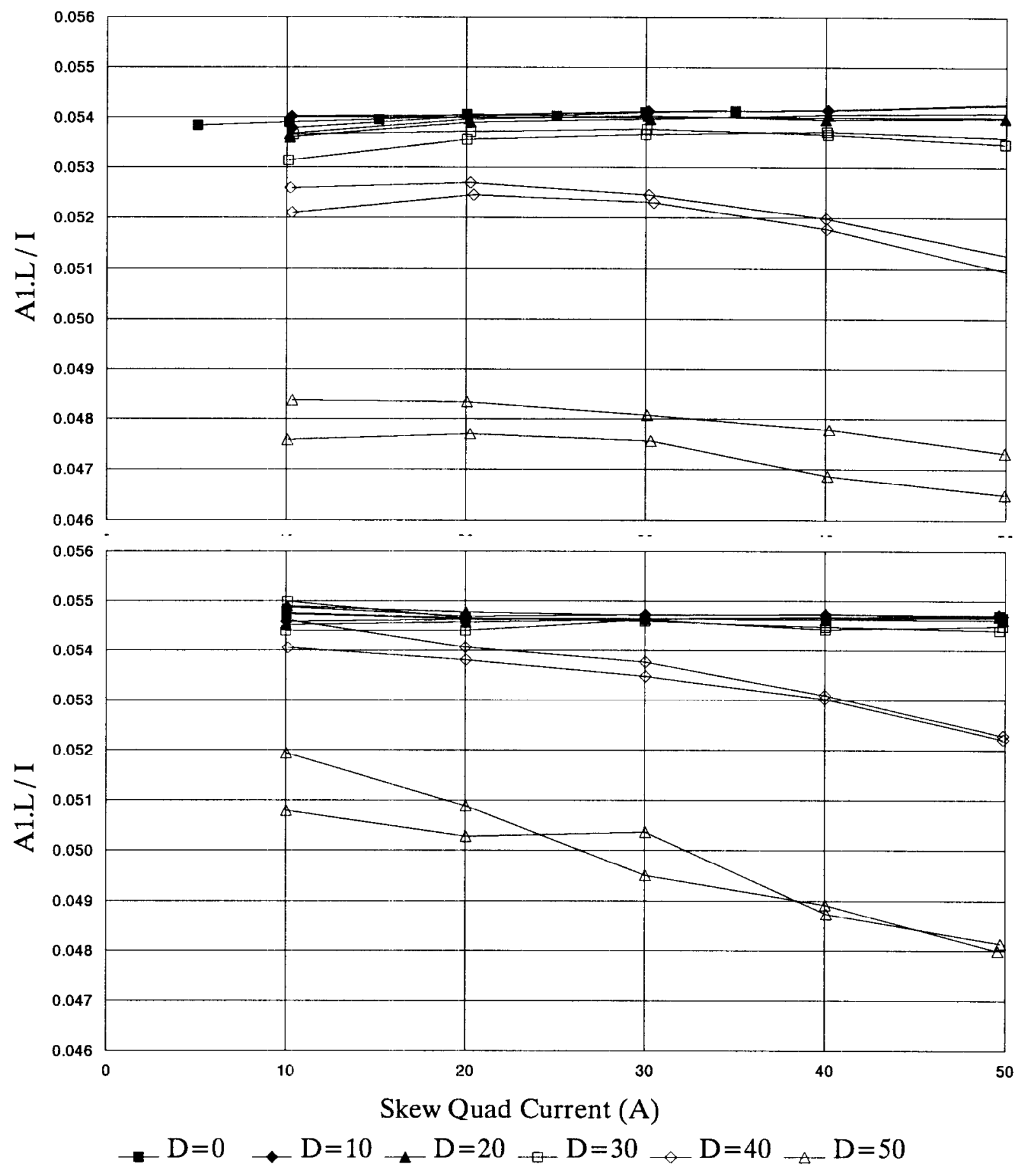

Figure 4. Skew quad transfer function, showing crossmodulation when the dipole windings are also powered. The separate curves are for different currents in the dipole windings ( $\mathrm{H}$ and $\mathrm{V}$ ). The data for two magnets are shown: BMSC25 (top) and BMSC26 (bottom). 


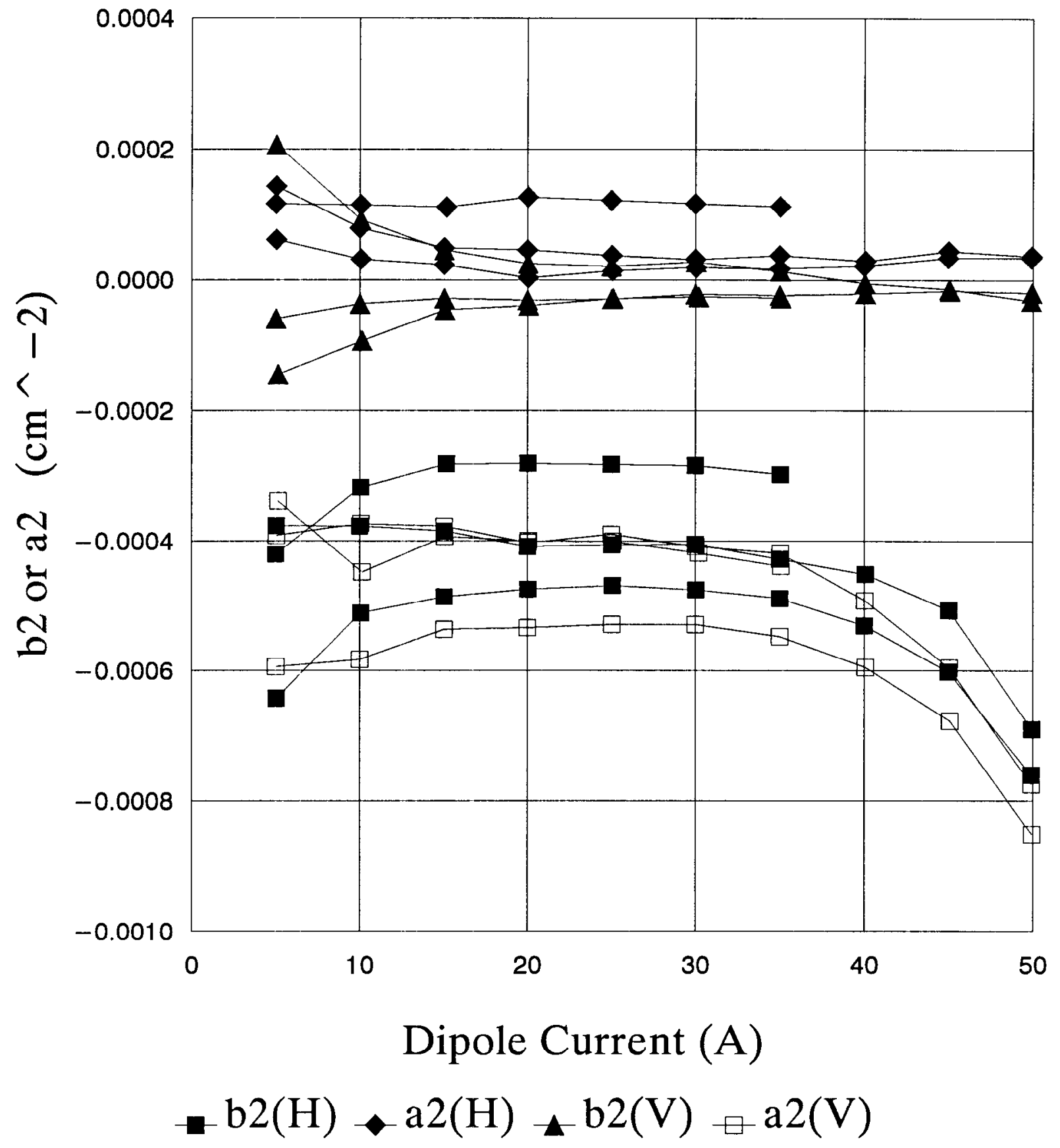

Figure 5. Relative sextupole coefficients for the standard corrector magnet with dipole excitation. The normal (b2) and skew (a2) sextupole are shown for both normal $(\mathrm{H})$ and skew $(\mathrm{V})$ dipole excitation. The sextupole component has approximately the same orientation (normal or skew) as the driven dipole. 


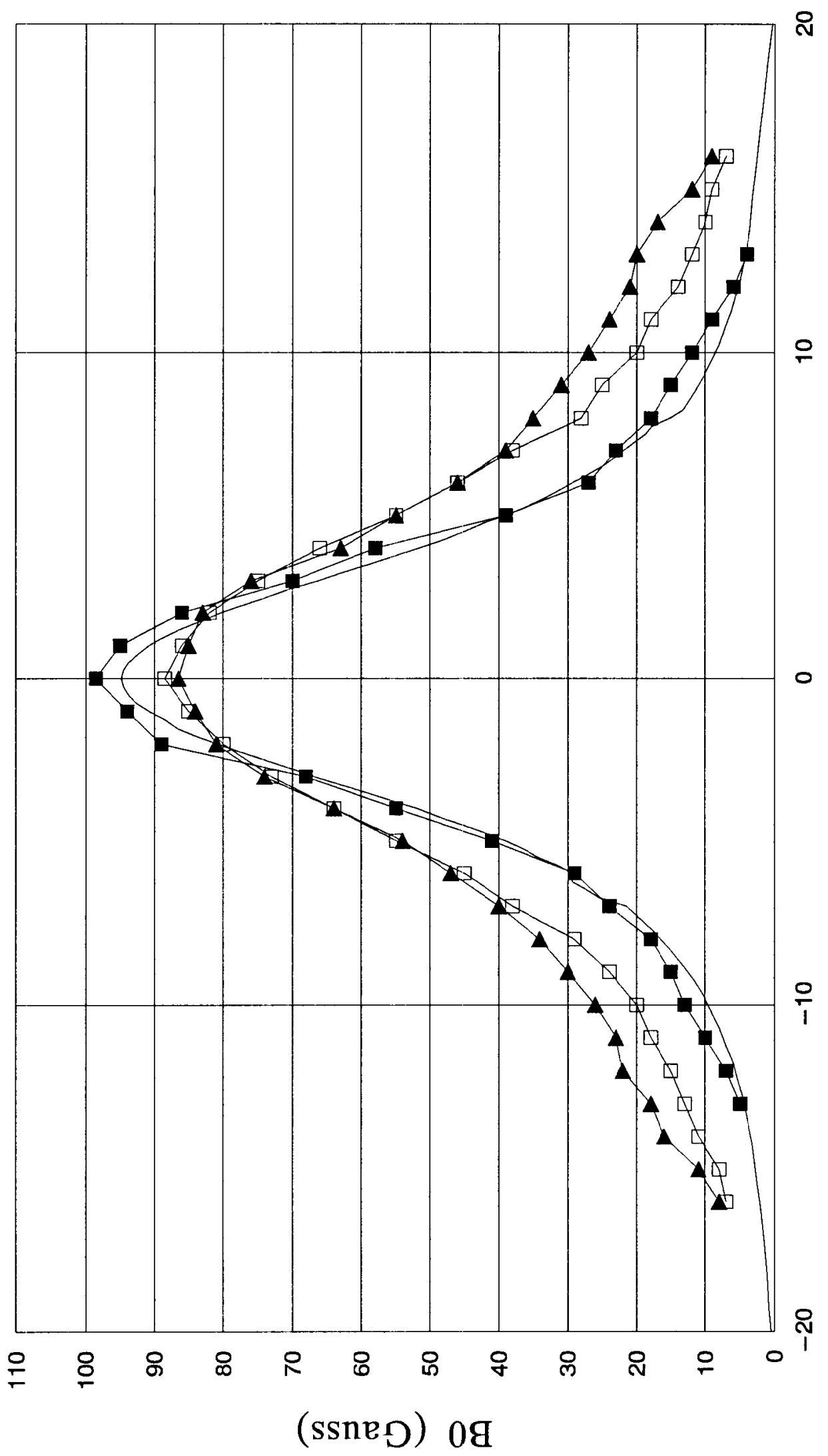

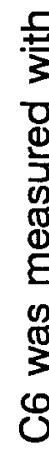

$\frac{\mathscr{d}}{8}$

$1 \frac{\overline{c 0}}{0}$

中 产

0 号

E $\quad$ 4

$\checkmark 0 \quad$ तั $\frac{0}{\sigma}$

而

む

$\checkmark \quad \mathbb{\Phi}$

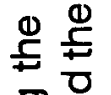

융 은

은

ญ Ф

跑

要

E

므 동

Ф민

कृ $\frac{5}{0}$

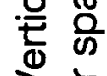

$>$ ळे

co 은

녹 동

号 


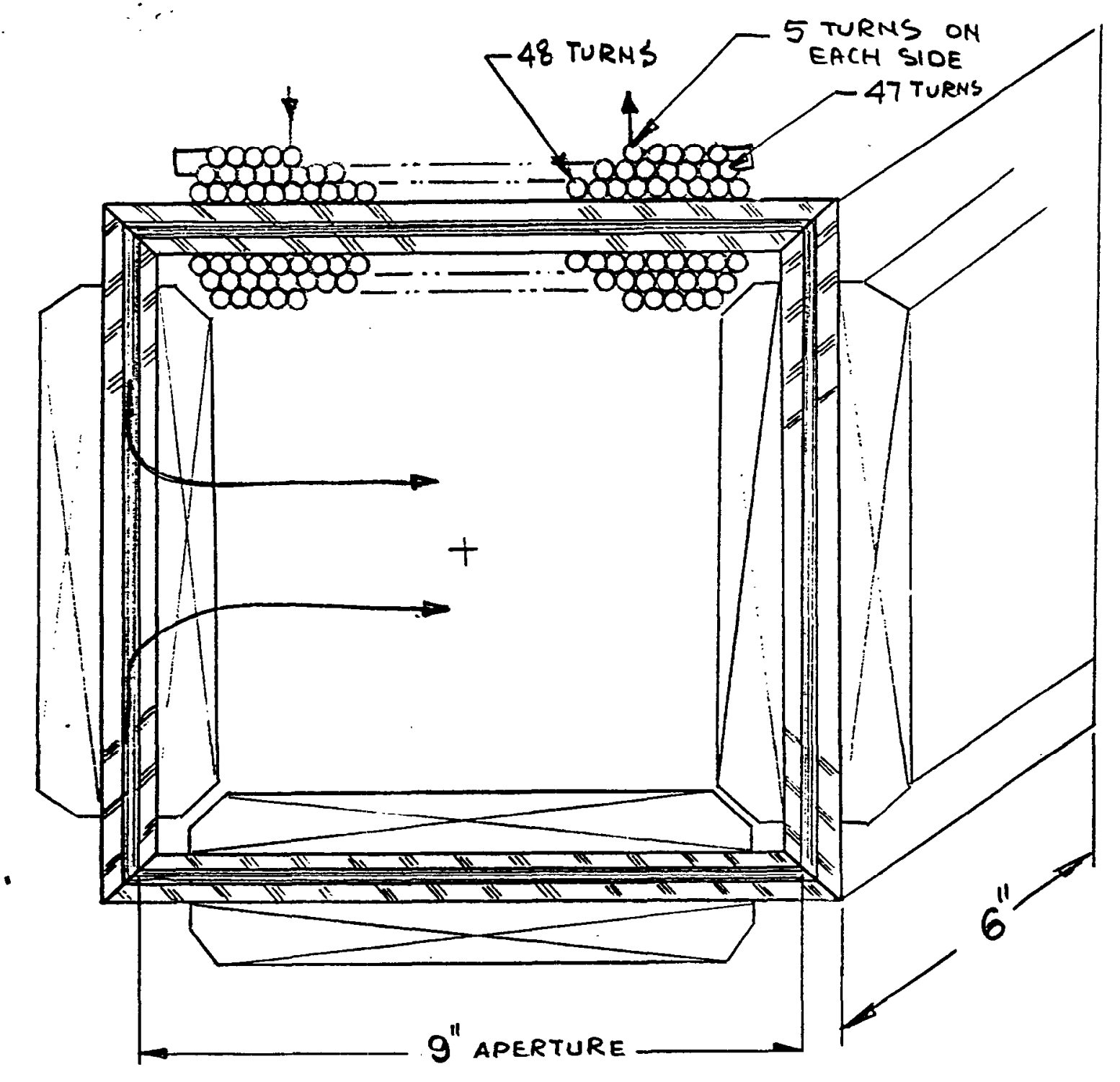

Figure 7. Standard Booster Ring Correction Magnet. The magnet is mounted rotated 45 degrees, and has separate windings for skew quad and either horizontal or vertical dipole. The iron is $0.25^{\prime \prime}$ thick. 


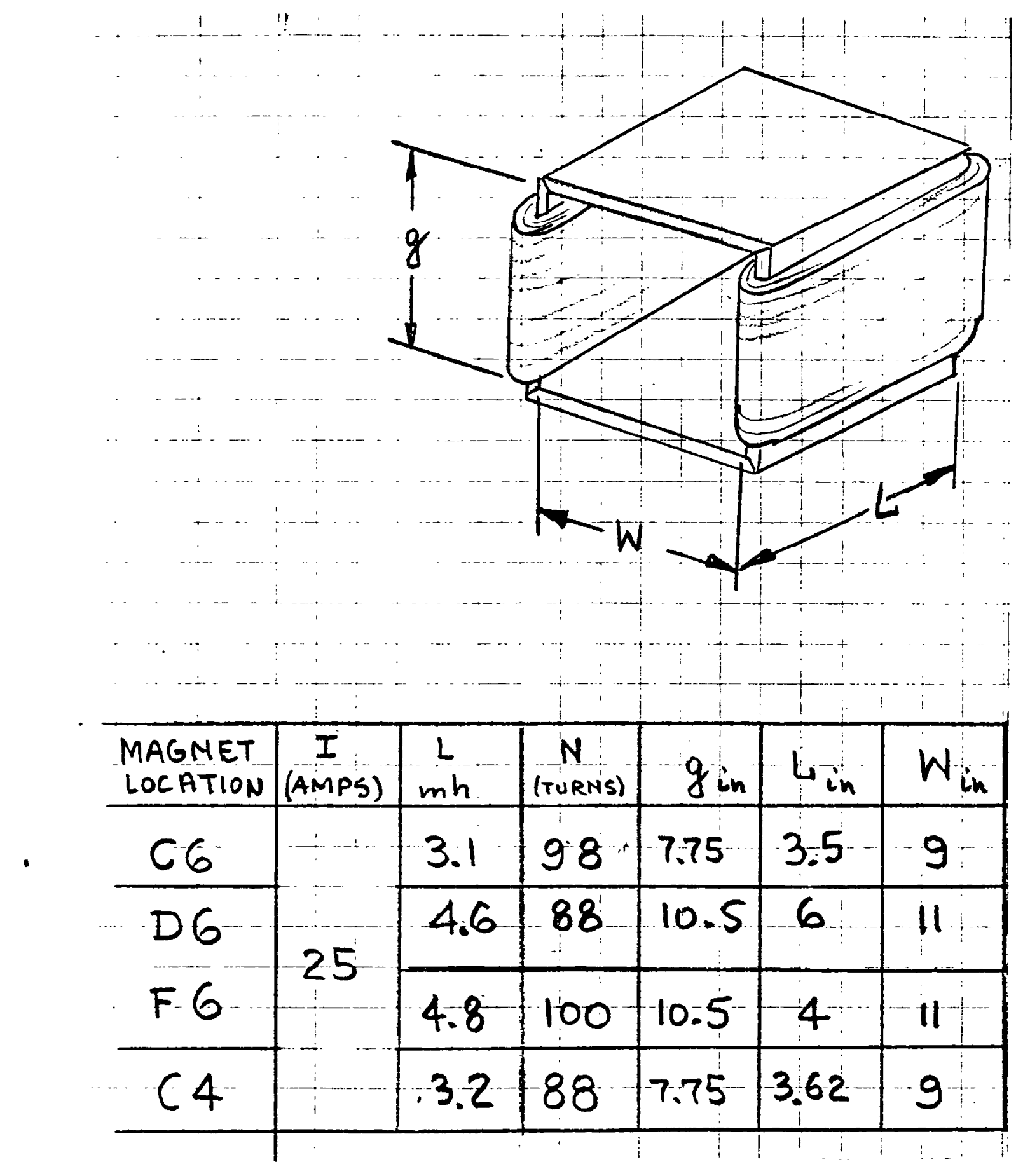

Figure 8. Dimensions of the four special correction magnets for the Booster ring. The iron is $0.25^{\prime \prime}$ thick. 